\title{
ICU-acquired weakness, diaphragm dysfunction and long-term outcomes of critically ill patients
}

\author{
Clément Saccheri ${ }^{1}$, Elise Morawiec ${ }^{1}$, Julie Delemazure ${ }^{1}$, Julien Mayaux¹, Bruno-Pierre Dubé2,3, \\ Thomas Similowski ${ }^{1,4}$, Alexandre Demoule ${ }^{1,4}$ and Martin Dres ${ }^{1,4^{*}}$
}

\begin{abstract}
Background: Intensive care unit (ICU)-acquired weakness and diaphragm dysfunction are frequent conditions, both associated with poor prognosis in critically ill patients. While it is well established that ICU-acquired weakness severely impairs long-term prognosis, the association of diaphragm dysfunction with this outcome has never been reported. This study investigated whether diaphragm dysfunction is associated with negative long-term outcomes and whether the coexistence of diaphragm dysfunction and ICU-acquired weakness has a particular association with 2-year survival and health-related quality of life (HRQOL).

Methods: This study is an ancillary study derived from an observational cohort study. Patients under mechanical ventilation were enrolled at the time of their first spontaneous breathing trial. Diaphragm dysfunction was defined by tracheal pressure generated by phrenic nerve stimulation $<11 \mathrm{cmH}_{2} \mathrm{O}$ and ICU-acquired weakness was defined by Medical Research Council (MRC) score $<48$. HRQOL was evaluated with the SF-36 questionnaire.

Results: Sixty-nine of the 76 patients enrolled in the original study were included in the survival analysis and 40 were interviewed. Overall 2-year survival was 67\% (46/69): 64\% (29/45) in patients with diaphragm dysfunction, 71\% (17/24) in patients without diaphragm dysfunction, 46\% (11/24) in patients with ICU-acquired weakness and 76\% (34/45) in patients without ICU-acquired weakness. Patients with concomitant diaphragm dysfunction and ICU-acquired weakness had a poorer outcome with a 2-year survival rate of 36\% (5/14) compared to patients without diaphragm function and ICU-acquired weakness [79\% (11/14) $(p<0.01)]$. Health-related quality of life was not influenced by the presence of ICU-acquired weakness, diaphragm dysfunction or their coexistence.
\end{abstract}

Conclusions: ICU-acquired weakness but not diaphragm dysfunction was associated with a poor 2-year survival of critically ill patients.

Keywords: Diaphragm dysfunction, Survival, Limb muscle weakness, Mortality, Quality of life

\section{Background}

Critically ill patients are likely to develop respiratory and limb muscle weakness [1]. It has been clearly established that intensive care unit (ICU)-acquired limb

\footnotetext{
*Correspondence: martin.dres@aphp.fr

1 Service de Pneumologie, Médecine intensive - Réanimation (Département "R3S"), AP-HP, Sorbonne Université, Groupe Hospitalier Universitaire Pitié-Salpêtrière Charles Foix, 75013 Paris, France Full list of author information is available at the end of the article
}

muscle weakness is a frequent condition, associated with poor prognosis [2-6]. Although the consequences of respiratory muscle weakness have been less extensively investigated, some evidences suggest that it may be a risk factor for prolonged duration of mechanical ventilation [7], associated with a higher risk of readmission [8] and higher mortality [9]. Diaphragm dysfunction is frequent in the intensive care unit (more than $60 \%$ of mechanically ventilated patients [10]) and is associated with difficult and prolonged weaning and poor 
prognosis [11-14]. Causes of diaphragm dysfunction are multifactorial and no specific treatment is currently available [10]. Diaphragm dysfunction is responsible for prolonged mechanical ventilation and may contribute to the development of "chronic critical illness", a devastating condition for patients and their families [15]. While the diaphragm undoubtedly plays a crucial role to ensure prompt and safe weaning from mechanical ventilation, recent data suggest that a substantial proportion of patients (up to $44 \%$ ) can be successfully weaned from the ventilator despite the presence of diaphragm dysfunction $[13,14,16]$. Nevertheless, in contrast with the reported negative impact of ICU-acquired weakness on long-term survival and disabilities $[3,4,17]$, it remains unclear whether diaphragm dysfunction per se is responsible for poor medium-term and long-term prognosis. The present study therefore used a previous cohort study conducted in our institution [13] to follow up mechanically ventilated patients in whom diaphragm and limb muscle functions were investigated at the time of liberation from mechanical ventilation. We tested the hypothesis that diaphragm dysfunction is associated with negative longterm outcomes and that the coexistence of diaphragm dysfunction and ICU-AW has a particular association on long-term prognosis, in line with the known negative synergistic effects of the two conditions on short-term prognosis.

\section{Methods}

This study was conducted in a 10-bed medical ICU in a university hospital. ICU patients were enrolled over an 8-month period and phone interviews were conducted over a 4-month period. The study was approved by the Comité de Protection des Personnes Ile-de-France VI (ID RCB: 2014-A00715-42) and was conducted in accordance with the ethical standards laid down in the 2008 Declaration of Helsinki. Informed consent was obtained from all patients or their relatives. Some data from this cohort have already been published elsewhere $[13,18,19]$.

\section{Initial study population}

As described elsewhere [13], patients were eligible for the study if they had been intubated and ventilated for at least $24 \mathrm{~h}$ and met the readiness-to-wean criteria as routinely assessed by the clinicians in charge on a daily basis according to current guidelines [20]. Patients presenting factors possibly interfering with tracheal pressure measurements in response to phrenic nerve stimulation (chest tubes, neuromuscular disease), tracheostomy, a contraindication to the phrenic nerve stimulation technique (pacemaker) and patients with withholding or withdrawal of life support decisions at the time of inclusion were not enrolled.
Diaphragm function and limb muscle strength were assessed on the same day once after enrolment and before starting the first spontaneous breathing trial. Diaphragm function was assessed by the change in tracheal pressure in response to magnetic stimulation (Ptr,stim), as described previously [13] and limb muscle strength was assessed by the Medical Research Council (MRC) score in patients screened for level of consciousness and understanding $[2,21]$. Patients with a Ptr,stim less than $11 \mathrm{~cm} \mathrm{H}_{2} \mathrm{O}$ were considered to have diaphragm dysfunction and patients with a Ptr,stim less than $7 \mathrm{cmH}_{2} \mathrm{O}$ were considered to have severe diaphragm dysfunction [18]. Patients with an MRC score less than 48 were considered to have ICU-AW [2].

\section{Data collection for long-term prognosis study}

Variables pertaining to patient characteristics and ICU stay were collected prospectively during hospitalization: age, sex, comorbidities, the Simplified Acute Physiology Score (SAPS II) and SOFA score computed at ICU admission [22, 23]. The dates of ICU admission, intubation, first spontaneous breathing trial, extubation, ICU discharge, hospital discharge and ICU and hospital death were obtained from the hospital medical charts. Survival and health-related quality of life assessment was performed as described below. Hospital medical charts were analysed to identify the patient's status (dead or alive) and dates over a 2-year period following inclusion in the study. Patients alive 2 years after inclusion were contacted by phone by the first author. The patient was asked to complete the Medical Outcomes Study 36-Item Short-Form Health Survey (SF-36) questionnaire to assess health-related quality of life $[24,25]$. The SF-36 questionnaire is a general quality of life questionnaire that evaluates physical and emotional quality of life. The SF-36 questionnaire includes eight multiple-item scales that assess physical functioning, social functioning, physical role, emotional role, mental health, pain, vitality, and general health [26]. Interviews were conducted by a single investigator blinded to the patient's status in relation to the presence of diaphragm dysfunction and ICUacquired weakness in the ICU.

\section{Study outcomes}

The primary outcome was 2-year overall survival following inclusion, and secondary outcomes were healthrelated quality of life and functional disability as assessed by the SF-36 score.

\section{Statistical analysis}

Due to the retrospective nature of this post hoc analysis, no sample size calculation could be made. All patients from the primary cohort [13] with available data were 
included in the present analysis. Continuous variables are expressed as median (interquartile range) and categorical variables are expressed as absolute and relative frequency. A normal distribution was checked by a Kolmogorov-Smirnov test. Continuous variables were compared by Mann-Whitney test and categorical variables were compared by Fisher's exact test. Kaplan-Meier survival curves were generated to describe cumulative survival following inclusion. Survival curves were compared by log-rank (Mantel-Cox) test.

Patient outcomes were compared by means of two classifications. First, patients were classified as follows: (1) with/without diaphragm dysfunction and (2) with/ without ICU-acquired weakness. In a secondary analysis, patients were also classified according to the co-existence of diaphragm dysfunction and ICU-acquired weakness: (a) diaphragm dysfunction only, (b) ICU-acquired weakness only, (c) co-existence of diaphragm dysfunction and ICU-acquired weakness and (d) neither of these two conditions.

Three exploratory analyses were then conducted. A first exploratory analysis assessed the 2-year survival in hospital survivors and a second exploratory analysis assessed the 2-year survival in patients with or without severe diaphragm dysfunction (Ptr,stim $<7 \mathrm{cmH}_{2} \mathrm{O}$ ). Last, a third exploratory analysis compared SF-36 questionnaire in patients with co-existence of diaphragm dysfunction and ICU-acquired weakness and those who were free from diseases. For all final comparisons, a $p$-value less than or equal to 0.05 was considered statistically significant. Statistical analyses were performed with Prism v.6, GraphPad Software.

\section{Results}

\section{Patient characteristics and follow-up}

Seventy-six patients were consecutively enrolled in the primary study (Fig. 1). Forty-eight (63\%) patients were diagnosed with diaphragm dysfunction at the time of weaning, 26 (34\%) had ICU-acquired weakness, 16 (21\%) had both diaphragm dysfunction and ICU-acquired weakness and 18 (24\%) were free of diseases. Patient characteristics are presented in Table 1. Patients had been ventilated for an average of 4 (2-6) days prior to inclusion. Patients who were free from diaphragm dysfunction and ICU-AW were more likely placed under mechanical ventilation for coma and were ventilated significantly shorter than others (Table 1). Overall, 43 (57\%) patients were successfully weaned from the ventilator after the first attempt. The mean length of ICU stay was 9 (4-18) days and the mean length of hospital stay

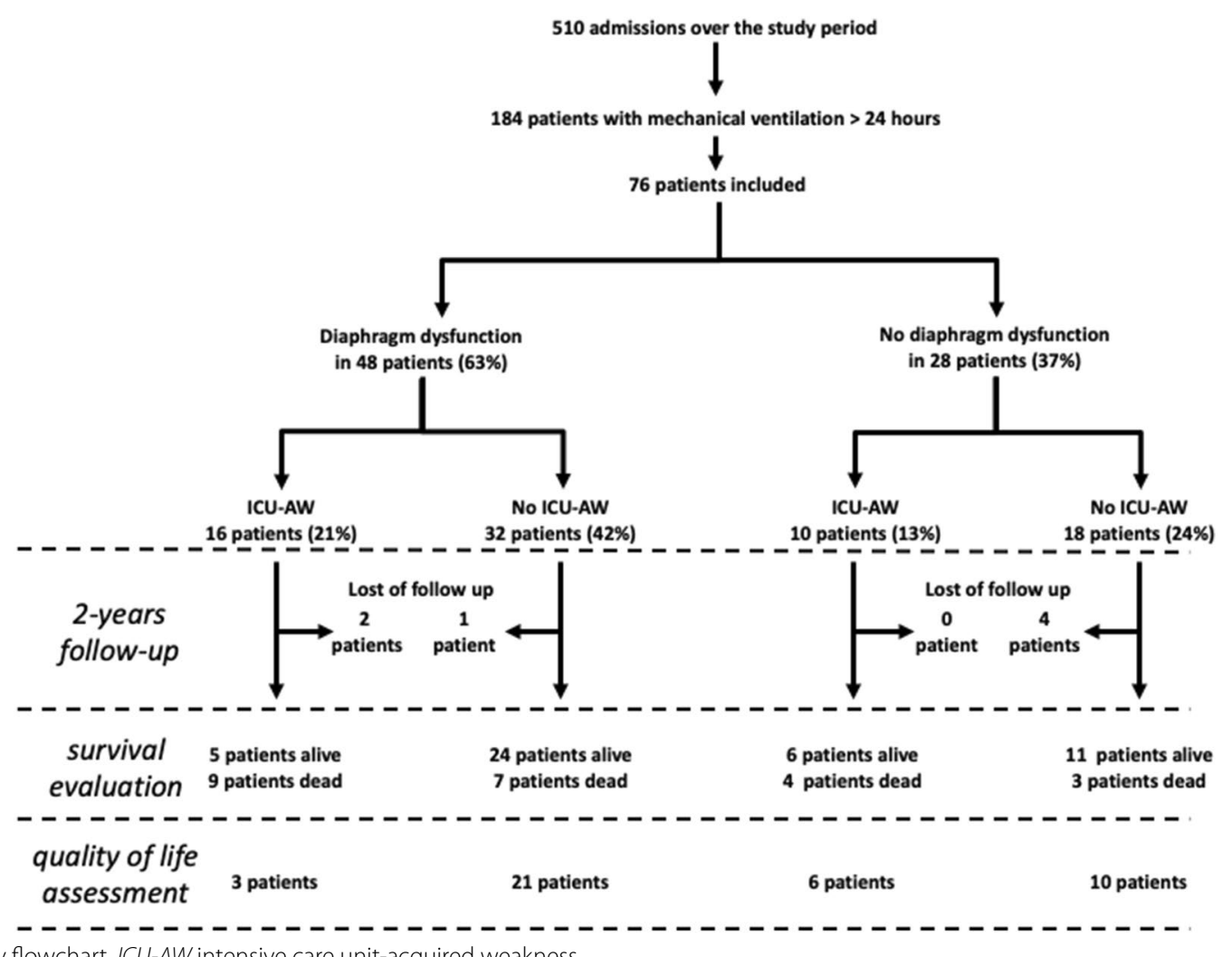

Fig. 1 Study flowchart. ICU-AW intensive care unit-acquired weakness 
Table 1 Characteristics and main outcomes of the study's population according to the presence of diaphragm dysfunction and intensive care unit-acquired weakness (ICU-AW) at time of liberation from mechanical ventilation

\begin{tabular}{|c|c|c|c|c|c|}
\hline \multirow[t]{2}{*}{ Characteristics and outcomes } & \multicolumn{2}{|c|}{ Diaphragm dysfunction } & \multicolumn{2}{|c|}{ No diaphragm dysfunction } & \multirow[t]{2}{*}{$p$} \\
\hline & $\begin{array}{l}\text { No ICU-AW } \\
N=32\end{array}$ & $\begin{array}{l}\text { ICU-AW } \\
N=16\end{array}$ & $\begin{array}{l}\text { No ICU-AW } \\
N=18\end{array}$ & $\begin{array}{l}\text { ICU-AW } \\
N=10\end{array}$ & \\
\hline Men, $n(\%)$ & $20(63)$ & $12(75)$ & $15(83)$ & $5(50)$ & 0.23 \\
\hline Age, years & $63(47-74)$ & $65(54-72)$ & $47(33-64)$ & $60(51-68)$ & 0.05 \\
\hline SAPS II upon admission & $44(24-64)$ & $43(28-67)$ & $32(15-42)$ & $37(26-63)$ & 0.18 \\
\hline SOFA upon admission & $4(3-7)$ & $5(5-7)$ & $5(4-5)$ & $6(4-10)$ & 0.47 \\
\hline Duration of MV at inclusion, days & $4(1-6)$ & $6(4-10)^{a}$ & $2(1-5)$ & $5(3-6)$ & $<0.01$ \\
\hline \multicolumn{6}{|l|}{ Main reason for admission, $n(\%)$} \\
\hline Acute respiratory failure & $17(53)$ & $8(50)$ & $3(17)$ & $3(30)$ & 0.06 \\
\hline Coma & $2(6)$ & $4(25)$ & $13(72)$ & $3(30)$ & $<0.01$ \\
\hline Shock & $13(41)$ & $4(25)$ & $2(11)$ & $4(40)$ & 0.14 \\
\hline \multicolumn{6}{|l|}{ Comorbidities, $n$ (\%) } \\
\hline Chronic respiratory disease & $8(25)$ & $2(13)$ & $2(11)$ & $0(0)$ & 0.23 \\
\hline Chronic cardiac disease & $7(22)$ & $3(19)$ & $2(11)$ & $0(0)$ & 0.36 \\
\hline Diabetes & $5(16)$ & $4(25)$ & $4(22)$ & $1(10)$ & 0.74 \\
\hline Immunocompromised & $6(19)$ & $6(38)$ & $3(16)$ & $3(30)$ & 0.42 \\
\hline Current smoking & $18(56)$ & $7(44)$ & $7(39)$ & $5(50)$ & 0.66 \\
\hline \multicolumn{6}{|l|}{ Limbs muscles strength } \\
\hline Medical Research Council score & $54(51-57)$ & $36(30-44)$ & $59(52-60)$ & $40(33-44)$ & - \\
\hline \multicolumn{6}{|l|}{ Diaphragm function } \\
\hline Ptr,stim, $\mathrm{cmH}_{2} \mathrm{O}$ & $7(6-8)$ & $6(3-8)$ & $14(13-20)$ & $12(11-17)$ & - \\
\hline \multicolumn{6}{|l|}{ Main outcomes } \\
\hline Total duration of MV, days & $6(3-12)$ & $10(5-22)^{a}$ & $2[1-5]$ & $7(5-20)^{a}$ & $<0.01$ \\
\hline Duration of ICU stay, days & $9(3-16)$ & $17(7-27)^{\mathrm{a}}$ & $4[3-10]$ & $13(8-27)$ & $<0.01$ \\
\hline Duration of hospital stay, days & $21(15-31)$ & $25(15-49)^{a}$ & $9[5-23]$ & $27(13-32)$ & 0.03 \\
\hline ICU survival, $n(\%)$ & $27 / 32(84)$ & $10 / 16(69)$ & 18/18 (100) & $8 / 10(80)$ & 0.33 \\
\hline Hospital survival, $n(\%)$ & $26 / 32(81)$ & $9 / 16(63)$ & 18/18 (100) & $8 / 10(80)$ & 0.02 \\
\hline Two-year survival, n (\%) & $24 / 31(77)$ & $5 / 14(36)$ & $11 / 14(79)$ & $6 / 10(60)$ & 0.03 \\
\hline
\end{tabular}

Categorical variables are expressed as absolute value (\%) and continuous variables are expressed as median (interquartile range [25-75\%])

$p$ values according to Kruskal-Wallis test for continuous variables and $\mathrm{Chi}$-2 for dichotomous variables

SAPS 2 Simplified Acute Physiology Score, SOFA Sequential Organ Failure Assessment score, MV mechanical ventilation, ICU intensive care unit, ICU-AW ICU-acquired weakness, Ptr,stim tracheal pressure during the phrenic nerves stimulation

a As compared to the group of 18 patients without diaphragm dysfunction neither ICU-AW

was 21 (10-30) days. All ICU survivors had been liberated from mechanical ventilation at the time of ICU discharge. As 7 patients were lost to follow-up, 2-year survival was assessed in only 69 patients and secondary outcomes (health-related quality of life) were assessed in 40 patients (Fig. 1).

\section{Two-year survival}

The overall 2-year survival was 67\% (46/69): 64\% (29/45) in patients with diaphragm dysfunction, $71 \%(17 / 24)$ in patients without diaphragm dysfunction, $46 \%(11 / 24)$ in patients with ICU-acquired weakness and 76\% (34/45) in patients without ICU-acquired weakness. Patients with co-existence of diaphragm dysfunction and ICU-acquired weakness had poorer survival than patients without diaphragm function and ICU-acquired weakness $(p=0.01$ for overall comparison, see Additional file 1: Figure S1). Survival was not significantly different between patients with diaphragm dysfunction and patients without diaphragm dysfunction (see Fig. 2a), but was significantly poorer in patients with ICU-acquired weakness compared to patients without ICU-acquired weakness (see Fig. 2b).

\section{Exploratory analysis restricted to hospital survivors}

Among the 76 patients enrolled in the study, 61 were alive at the time of hospital discharge. From them, 7 were lost of follow-up leading to a sample of 54 patients in the 


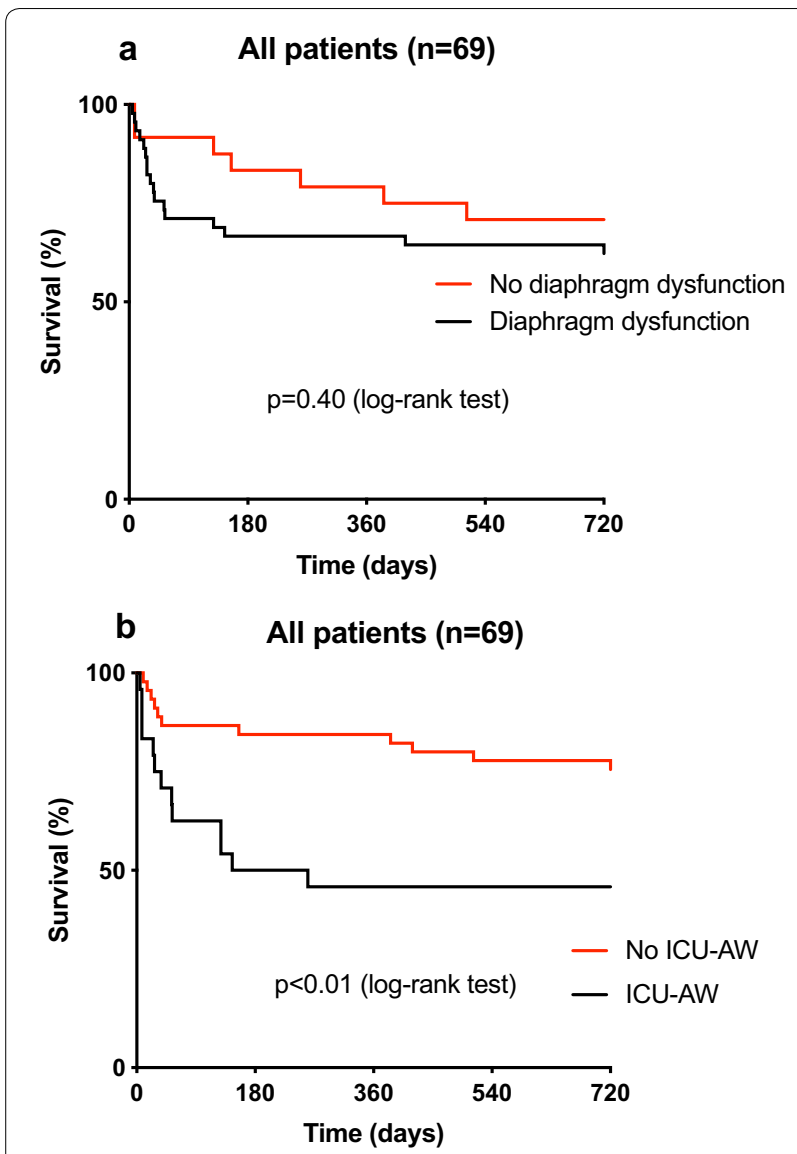

Fig. 2 Kaplan-Meier 2-year survival curves in patients with and without diaphragm dysfunction (a) and in patients with and without ICU-AW (b)

exploratory analysis (see Fig. 3 and Additional file 1: Figure S2). Although the comparison between groups was not significant, the findings were in line with the primary analysis.

\section{Exploratory analysis conducted on patients with severe diaphragm dysfunction}

A severe diaphragm dysfunction (Ptr,stim $<7 \quad \mathrm{cmH}_{2} \mathrm{O}$ ) was diagnosed in $31 \%(24 / 76)$ of the patients. The survival between patients with and without severe diaphragm dysfunction was not significantly different $(p=0.07)$ (see Additional file 1: Figure S3).

\section{Health-related quality of life}

The SF-36 questionnaire was completed at the end of the study in 40 patients. Figure 4 displays the values of the SF-36 components (mental and physical) in patients with and without diaphragm dysfunction and in patients with and without ICU-acquired weakness. No significant difference in terms of SF-36 categories was observed between groups. The exploratory analysis comparing

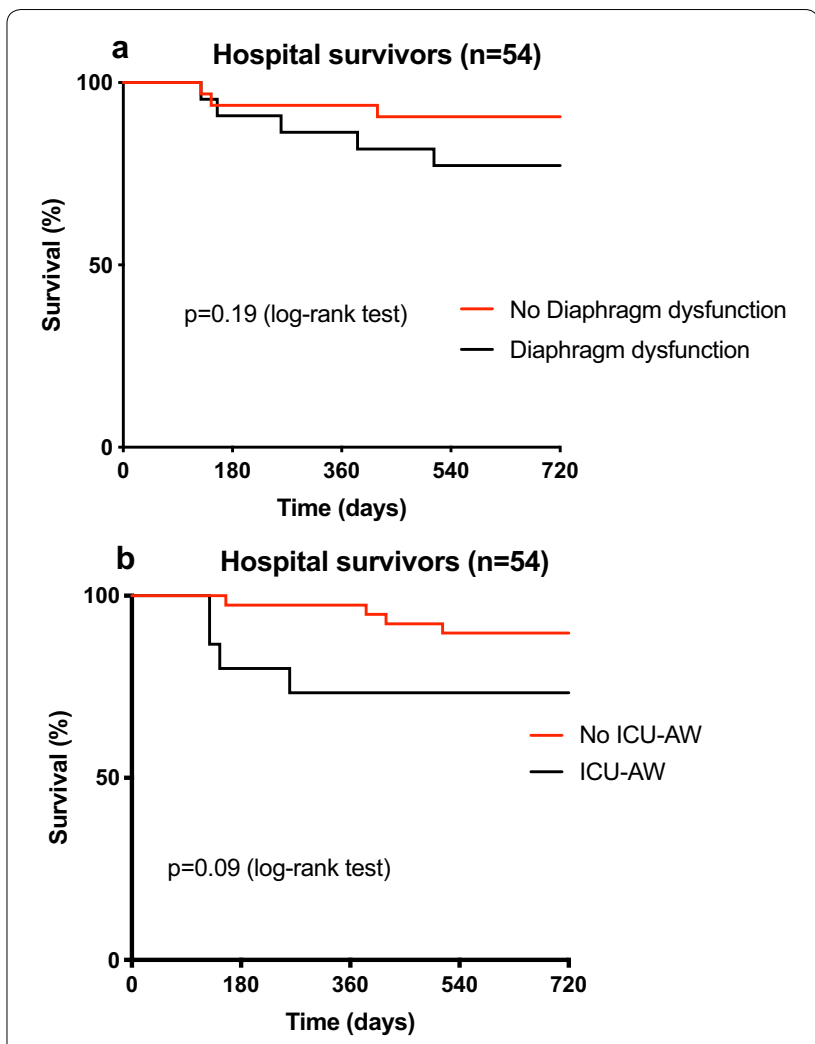

Fig. 3 Kaplan-Meier 2-year survival curves in patients with and without diaphragm dysfunction (a) and in patients with and without ICU-AW (b) (sensitivity analysis restricted to hospital survivors)

patients with co-existence of diaphragm dysfunction and ICU-acquired weakness and those who were free from diseases found no difference in term of SF-36 mental and physical components (see Additional file 1: Figure S4).

\section{Discussion}

This study reports the long-term-up to 2 years-survival and health-related quality of life of critically ill patients with diaphragm dysfunction, ICU-acquired weakness or a combination of the two at the time of liberation from mechanical ventilation. The main findings can be summarized as follows: (1) 2-year survival was much better in patients without diaphragm dysfunction and ICU-acquired weakness at the time of liberation from mechanical ventilation than in patients presenting both of these conditions ( $79 \%$ versus $36 \%$, respectively); (2) survival was not significantly different between patients with diaphragm dysfunction without ICU-acquired weakness and patients not presenting either of the two conditions ( $77 \%$ versus $79 \%$, respectively); (3) survival appeared to be much more markedly influenced by the presence of ICU-acquired weakness than by the presence of diaphragm dysfunction and (4) the study failed 


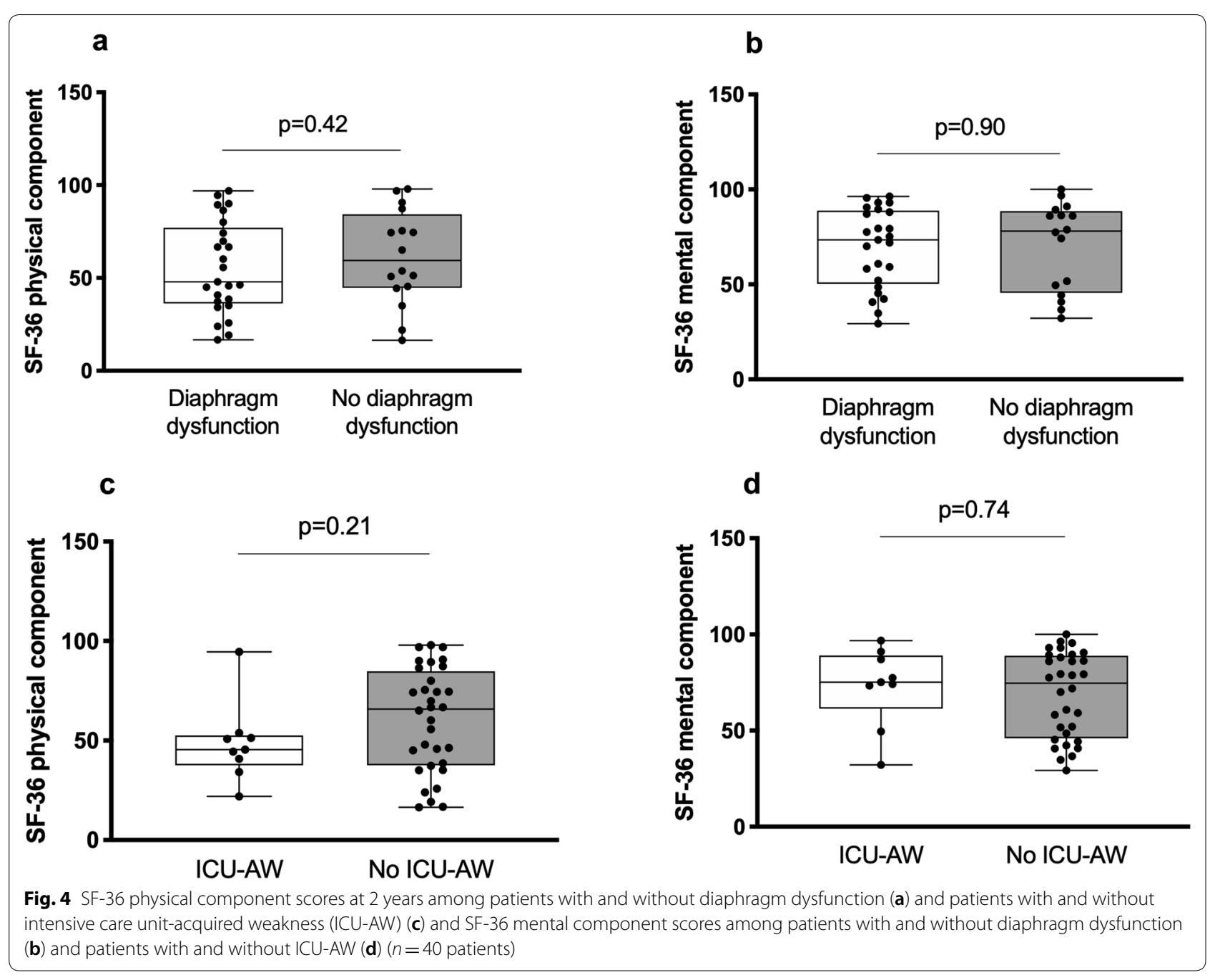

to demonstrate any difference in terms of health-related quality of life according to the presence of diaphragm dysfunction and/or ICU-acquired weakness.

Only a few studies have examined the association between ICU-acquired weakness and long-term survival. Sharshar et al. reported an in-hospital survival of $77 \%$ in patients with ICU-acquired weakness [17] and Ali et al. reported an in-hospital survival of $69 \%$ [3]. In a study with prolonged follow-up (up to 1 year), Hermans et al. reported a $68 \%$ survival rate in patients with ICUacquired weakness [4]. In our study, patients with ICUacquired weakness had a 2 -year survival of $46 \%$. This lower survival rate in our cohort could be explained by the timing of the assessment of ICU-acquired weakness (earlier in our study than in other studies) and the prolonged duration of follow-up. It remains unclear whether diaphragm dysfunction is one of several features of ICUacquired weakness or whether the two conditions are distinct $[7,13,27]$. Two studies conducted at the time of weaning demonstrated a weak but significant correlation between diaphragm function and limb muscle strength $[13,14]$. One of these studies also suggested a difference in prognosis between the two conditions, as ICU-acquired weakness was more strongly associated with prolonged hospital stay and duration of mechanical ventilation, while diaphragm dysfunction was mostly associated with difficult/prolonged weaning and ICU and hospital mortality [13]. The present study reports novel findings in this context, suggesting that ICU-acquired weakness may be associated with a more severe impact on long-term outcome than diaphragm dysfunction. The association of diaphragm dysfunction with longterm prognosis has never been previously investigated. One study investigated the impact of global respiratory weakness (as assessed by the maximal inspiratory pressure) and reported a higher 1-year mortality (31\%) in the group of patients with low maximal inspiratory pressure compared to patients with high maximal inspiratory 
pressure, in whom the 1-year mortality was 7\% [9]. However, limb muscle strength was not analysed in this study. Our findings suggest that the long-term prognosis of these patients is mainly driven by the presence of ICUacquired weakness rather than diaphragm dysfunction. Nevertheless, as expected, the co-existence of these two conditions was associated with a poor survival. The presence of diaphragm dysfunction in critically ill patients has been associated with poor short-term prognosis in some studies [11, 13, 14, 28], but not in others [29, 30]. Remarkably, a recent study demonstrated that diaphragm dysfunction was not associated with an increased risk of extubation failure in patients who successfully passed the weaning trial [29], which is in line with our findings, suggesting that diaphragm function is a critical determinant in the outcome of the weaning trial, but once patients have been weaned from the ventilator, the long-term prognosis is mainly determined by other risk factors, notably ICU-acquired weakness.

Our study also investigated the respective association of ICU-acquired weakness and diaphragm dysfunction with health-related quality of life and indicated that health-related quality of life was not significantly different 2 years after the ICU stay regardless of the presence or absence of diaphragm dysfunction or ICU-acquired weakness. These findings are in contrast with previous data reporting substantial impairments in physical function and health-related quality of life in acute lung injury survivors [31]. This discrepancy may be explained by the timing of ICU-acquired weakness evaluation (after a few days of mechanical ventilation in our study as compared to 3 months after the acute lung injury in the study by Fan et al.) and the different period of time for both investigations (2014-2015 in our study versus 2004-2007 in the study by Fan et al.) [31]. Although not statistically significant, the SF-36 questionnaire score indicated better health-related quality of life in patients not presenting either of these two conditions. Importantly, this difference may be underestimated by the competitive risk of death. The findings of this study could possibly be explained by a lack of power, but they could also be the consequence of self-adaptive quality of life perception [32]. Eventually, the findings on SF-36 questionnaire should be considered as an exploratory analysis according to the sample size and warrant further studies.

\section{Strengths and limitations}

The main strength of our study is the phrenic nerve stimulation that was used to evaluate diaphragm function, and this method is considered to be the reference method in the ICU. In addition, our study provides insight into the association of diaphragm dysfunction and ICUacquired weakness with survival and quality of life over a long period of time after the ICU stay. However, some limitations must be acknowledged. The first and main limitation concerns the small sample size finally analysed. Indeed, this is a cohort study with a significant risk of confounding and relatively small event rates. As such the statistical analyses do not adjust for potential confounding and explore simple associations. Our findings must therefore be interpreted cautiously and larger studies are warranted. Secondly, diaphragm function and limb muscle strength were not repeatedly assessed in our study. Consequently, the findings in terms of survival and quality of life could not be correlated with possible recovery of either diaphragm function or limb muscle strength. Thirdly, ICU-acquired weakness was assessed with MRC score that relies on the cooperation of the patients. Therefore, even if patients were confirmed awake, it is a volitional measurement that may be associated with a ceiling effect and poor responsiveness. Fourthly, due to small size of the cohort, competing risk of death could not be take into account which may have created a bias in the assessment of health care quality of life.

\section{Conclusion}

At the time of starting the process of weaning from mechanical ventilation, diaphragm dysfunction and ICU-acquired weakness were associated with distinct outcomes. ICU-acquired weakness was associated with a poorer 2-year survival of critically ill patients than diaphragm dysfunction, whereas the presence of diaphragm dysfunction appears to be more likely a determinant of early prognosis. Eventually, the co-existence of both diseases was associated with the worse outcome.

\section{Supplementary information}

Supplementary information accompanies this paper at https://doi. org/10.1186/s13613-019-0618-4.

Additional file 1: Figure S1. Kaplan-Meier two-year survival curves in patients with diaphragm dysfunction, intensive care unit-acquired weakness (ICU-AW), no disease or both diseases. Figure S2. Kaplan-Meier twoyear survival curves in patients with diaphragm dysfunction, intensive care unit-acquired weakness (ICU-AW), no disease or both (sensitivity analysis restricted to hospital survivors). Figure S3. Kaplan-Meier two-year survival curves in patients with and without severe diaphragm dysfunction as defined by a change in tracheal pressure in response to magnetic stimulation $<7 \mathrm{cmH} 2 \mathrm{O}$. Figure S4. SF-36 physical component scores at two years among patients with diaphragm dysfunction only, with intensive care unit acquired weakness only, with none of the diseases and with both diseases (panel A) and SF-36 mental component scores among patients with diaphragm dysfunction only, with intensive care unit acquired weakness only, with none of the diseases and with both diseases (panel B) $(n=40$ patients).

\section{Abbreviations}

Ptr,stim: tracheal pressure in response to bilateral magnetic stimulation of the phrenic nerves; ICU: intensive care unit; HRQOL: health-related quality of life; SF-36: Short Form (36) Health Survey. 


\section{Acknowledgements \\ None.}

\section{Authors' contributions}

MD designed the study. MD, CS and EM coordinated the study. MD, BPD, EM $J D$ and JM were responsible for patient screening, enrollment, and follow-up. $M D, A D, C S, E M$ and TS analysed the data. MD, CS, AD, EM and TS wrote the manuscript. All authors had full access to all study data, contributed to drafting the manuscript or critical revision of it for important intellectual content, approved the final version of the manuscript, and take responsibility for the integrity of the data and the accuracy of the data analysis. All authors read and approved the final manuscript.

\section{Funding}

M.D. was supported by the French Intensive Care Society, Paris, France (bourse de mobilité 2015); The 2015 Short Term Fellowship program of the European Respiratory Society, Lausanne, Switzerland; The 2015 Bernhard Dräger Award for advanced treatment of acute respiratory failure of the European Society of Intensive Care Medicine, Brussels, Belgium; the Assistance Publique Hôpitaux de Paris, Paris, France and the Fondation pour la Recherche Médicale, Paris, France (FDM 20150734498).

\section{Availability of data and materials}

The datasets used and/or analysed during the current study are available from the corresponding author on reasonable request.

\section{Ethics approval and consent to participate}

Human research ethics committee approval for the study was provided by the Comité de Protection des Personnes - lle de France 6.

\section{Consent for publication}

Patients or their next of kin gave informed consent.

\section{Competing interests}

AD reports personal fees and non-financial support from Medtronic; grants, personal fees and non-financial support from Philips; personal fees from Baxter; personal fees from Hamilton; grants and non-financial support from Fisher \& Paykel; grants from the French Ministry of Health. MD received personal fees from Lungpacer Inc. BPD received personal fees from Grifols, Boehringer Ingelheim and Roche, and has signed clinical research contracts with Sanofi, Roche and Boehringer Ingelheim. Thomas Similowski has received personal fees from Lungpacer Inc. and is a member of the board of a research association that has received, over the past ten years, unrestricted research grants from Maquet, Hamilton, Covidien, and Philips. He is the head of a research unit (UMRS 1158) that has signed research contracts with Air Liquide Medical Systems, France; he is listed as inventor or co-inventor on several patents, granted or pending, describing a brain-ventilator interface. LB's Research Laboratory received research grants from Covidien, General Electric, Fisher Paykel, Maquet (with St Michael's Hospital) and Philips. The other authors have no conflict of interest to disclose.

\section{Author details}

${ }^{1}$ Service de Pneumologie, Médecine intensive - Réanimation (Département "R3S"), AP-HP, Sorbonne Université, Groupe Hospitalier Universitaire Pitié-Salpêtrière Charles Foix, 75013 Paris, France. ${ }^{2}$ Département de médecine, service de pneumologie, hôpital Hôtel-Dieu du Centre Hospitalier de l'Université de Montréal, Montreal, QC, Canada. ${ }^{3}$ Centre de Recherche du Centre Hospitalier de l'Université de Montréal - Carrefour de l'Innovation et de l'Évaluation en santé, Montreal, QC, Canada. ${ }^{4}$ UMRS1158 Neurophysiologie respiratoire expérimentale et clinique, Sorbonne Université, Paris, France.

Received: 5 October 2019 Accepted: 16 December 2019

Published online: 03 January 2020

\section{References}

1. Latronico N, Bolton CF. Critical illness polyneuropathy and myopathy: a major cause of muscle weakness and paralysis. Lancet Neurol. 2011:10:931-41.
2. De Jonghe B, Sharshar T, Lefaucheur J-P, Authier F-J, Durand-Zaleski I, Boussarsar $\mathrm{M}$, et al. Paresis acquired in the intensive care unit: a prospective multicenter study. JAMA. 2002;288:2859-67.

3. Ali NA, O'Brien JM, Hoffmann SP, Phillips G, Garland A, Finley JCW, et al. Acquired weakness, handgrip strength, and mortality in critically ill patients. Am J Respir Crit Care Med. 2008;178:261-8.

4. Hermans G, Van Mechelen H, Clerckx B, Vanhullebusch T, Mesotten D, Wilmer A, et al. Acute outcomes and 1-year mortality of intensive care unit-acquired weakness. A cohort study and propensity-matched analysis. Am J Respir Crit Care Med. 2014;190:410-20.

5. Puthucheary ZA, Rawal J, McPhail M, Connolly B, Ratnayake G, Chan $P$, et al. Acute skeletal muscle wasting in critical illness. JAMA. 2013:310:1591-600.

6. Dos Santos C, Hussain SNA, Mathur S, Picard M, Herridge M, Correa J, et al. Mechanisms of chronic muscle wasting and dysfunction after an intensive care unit stay. A pilot study. Am J Respir Crit Care Med. 2016;194:821-30.

7. De Jonghe B, Bastuji-Garin S, Durand M-C, Malissin I, Rodrigues P, Cerf C, et al. Respiratory weakness is associated with limb weakness and delayed weaning in critical illness. Crit Care Med. 2007:35:2007-15.

8. Adler D, Dupuis-Lozeron E, Richard J-C, Janssens J-P, Brochard L. Does inspiratory muscle dysfunction predict readmission after intensive care unit discharge? Am J Respir Crit Care Med. 2014;190:347-50.

9. Medrinal C, Prieur G, Frenoy É, Robledo Quesada A, Poncet A, Bonnevie T, et al. Respiratory weakness after mechanical ventilation is associated with one-year mortality —a prospective study. Crit Care. 2016;20:231.

10. Dres M, Goligher EC, Heunks LMA, Brochard LJ. Critical illness-associated diaphragm weakness. Intensive Care Med. 2017;43:1441-52.

11. Goligher EC, Dres M, Fan E, Rubenfeld GD, Scales DC, Herridge MS, et al. Mechanical ventilation-induced diaphragm atrophy strongly impacts clinical outcomes. Am J Respir Crit Care Med. 2018:197:204-13.

12. Kim WY, Suh HJ, Hong S-B, Koh Y, Lim C-M. Diaphragm dysfunction assessed by ultrasonography: influence on weaning from mechanical ventilation. Crit Care Med. 2011;39:2627-30.

13. Dres M, Dubé B-P, Mayaux J, Delemazure J, Reuter D, Brochard L, et al. Coexistence and impact of limb muscle and diaphragm weakness at time of liberation from mechanical ventilation in medical intensive care unit patients. Am J Respir Crit Care Med. 2017;195:57-66.

14. Jung B, Moury PH, Mahul M, de Jong A, Galia F, Prades A, et al. Diaphragmatic dysfunction in patients with ICU-acquired weakness and its impact on extubation failure. Intensive Care Med. 2016;42(5):853-861.

15. Nelson JE, Cox CE, Hope AA Carson SS. Chronic critical illness. Am J Respir Crit Care Med. 2010;182:446-54

16. Laghi F, Cattapan SE, Jubran A, Parthasarathy S, Warshawsky P, Choi YSA, et al. Is weaning failure caused by low-frequency fatigue of the diaphragm? Am J Respir Crit Care Med. 2003;167:120-7.

17. Sharshar T, Bastuji-Garin S, Stevens RD, Durand M-C, Malissin I, Rodriguez $P$, et al. Presence and severity of intensive care unit-acquired paresis at time of awakening are associated with increased intensive care unit and hospital mortality. Crit Care Med. 2009;37:3047-53.

18. Dres M, Goligher EC, Dubé B-P, Morawiec E, Dangers L, Reuter D, et al, Diaphragm function and weaning from mechanical ventilation: an ultrasound and phrenic nerve stimulation clinical study. Ann Intensive Care. 2018;8:53.

19. Dubé B-P, Dres M, Mayaux J, Demiri S, Similowski T, Demoule A. Ultrasound evaluation of diaphragm function in mechanically ventilated patients: comparison to phrenic stimulation and prognostic implications. Thorax. 2017;72:811-8.

20. Boles J-M, Bion J, Connors A, Herridge M, Marsh B, Melot C, et al. Weaning from mechanical ventilation. Eur Respir J. 2007;29:1033-56.

21. Hermans G, Clerckx B, Vanhullebusch T, Segers J, Vanpee G, Robbeets

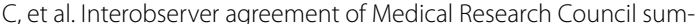
score and handgrip strength in the intensive care unit. Muscle Nerve. 2012:45:18-25.

22. Vincent JL, de Mendonça A, Cantraine F, Moreno R, Takala J, Suter PM, et al. Use of the SOFA score to assess the incidence of organ dysfunction/ failure in intensive care units: results of a multicenter, prospective study. In: Working group on "sepsis-related problems" of the European Society of Intensive Care Medicine. Crit Care Med. 1998;26:1793-800. 
23. Le Gall JR, Lemeshow S, Saulnier F. A new simplified acute physiology score (SAPS II) based on a European/North American multicenter study. JAMA. 1993;270:2957-63.

24. Zatzick DF, Marmar CR, Weiss DS, Browner WS, Metzler TJ, Golding JM, et al. Posttraumatic stress disorder and functioning and quality of life outcomes in a nationally representative sample of male Vietnam veterans. Am J Psychiatry. 1997;154:1690-5.

25. Gandek B, Sinclair SJ, Kosinski M, Ware JE. Psychometric evaluation of the SF-36 health survey in Medicare managed care. Health Care Financ Rev. 2004;25:5-25

26. Davidson TA, Caldwell ES, Curtis JR, Hudson LD, Steinberg KP. Reduced quality of life in survivors of acute respiratory distress syndrome compared with critically ill control patients. JAMA. 1999;281:354-60.

27. Medrinal C, Prieur G, Frenoy É, Combret Y, Gravier FE, Bonnevie T, et al. Is overlap of respiratory and limb muscle weakness at weaning from mechanical ventilation associated with poorer outcomes? Intensive Care Med. 2017:43:282-3.

28. DiNino E, Gartman EJ, Sethi JM, McCool FD. Diaphragm ultrasound as a predictor of successful extubation from mechanical ventilation. Thorax. 2014;69:423-7.
29. Vivier E, Muller M, Putegnat J-B, Steyer J, Barrau S, Boissier F, et al. Inability of diaphragm ultrasound to predict extubation failure: a multicenter study. Chest. 2019;155:1131-9.

30. Moury P-H, Cuisinier A, Durand M, Bosson J-L, Chavanon O, Payen J-F, et al. Diaphragm thickening in cardiac surgery: a perioperative prospective ultrasound study. Ann Intensive Care. 2019;9:50.

31. Fan E, Dowdy DW, Colantuoni E, Mendez-Tellez PA, Sevransky JE, Shanholtz C, et al. Physical complications in acute lung injury survivors: a two-year longitudinal prospective study. Crit Care Med. 2014;42:849-59.

32. De Abrantes-Pais FN, Friedman JK, Lovallo WR, Ross ED. Psychological or physiological: why are tetraplegic patients content? Neurology. 2007;69:261-7.

\section{Publisher's Note}

Springer Nature remains neutral with regard to jurisdictional claims in published maps and institutional affiliations.

\section{Submit your manuscript to a SpringerOpen ${ }^{\circ}$ journal and benefit from:}

- Convenient online submission

- Rigorous peer review

- Open access: articles freely available online

- High visibility within the field

- Retaining the copyright to your article

Submit your next manuscript at $\boldsymbol{\nabla}$ springeropen.com 